\title{
Resposta vacinal a EMA-2 recombinante de Theileria equi em éguas gestante primovacinadas e revacinadas
}

Alice Correa Santos;, Fábio Leivas Leite, Ana Muñoz Vianna, Guilherme Borges Weege, Bruna dos Santos Suñe Moraes, Ilusca

Sampaio Finger, Vitória Müller, Carlos Eduardo Wayne Nogueira

Universidade Federal de Pelotas (UFPel), Pelotas, RS, Brasil

*Autor correspondente

e-mail: alice.cs@live.com

\section{Resumo}

Theileria equi é um protozoário hemoparasita, causador de piroplasmose equina, uma doença de importante impacto sanitário e econômico no mercado equestre. Na gestação, T. equi é prejudicial à saúde da égua, além de causar abortos e danos ao neonato. A vacina rEMA-2 foi desenvolvida experimentalmente como uma alternativa de imunógeno, utilizando o antígeno de superfície de merozoítos primariamente reconhecido pelo sistema imunológico de equino, EMA-2. 0 objetivo deste estudo foi comparar a resposta imune humoral à vacina contendo a proteína rEMA-2 de T. equi em éguas gestantes sob a condição de primovacinação e revacinação, bem como a concentração de anticorpos vacinais no colostro. A vacina rEMA-2 foi produzida experimentalmente, sendo composta de 200ng/ $\mu$ l de rEMA-2, PBS-T e Hidróxido de Alumínio como adjuvante. Foram utilizadas 17 éguas gestantes, divididas em Grupo Primovacinado ( $\mathrm{n}=7$ ), Grupo Revacinado ( $n=4$ ) e Grupo Controle ( $n=5$ ), onde as éguas do Grupo Revacinado receberam reforço um ano após a primovacinação. 0 esquema vacinal foi realizado a partir dos 300 dias de gestação, com três doses em intervalos de 21 dias nos grupos vacinados. Em todos os grupos, semanalmente foi coletado, separado e armazenado o soro sanguíneo a $-20^{\circ} \mathrm{C}$. 0 colostro foi obtido através de ordenha logo após o parto e antes da primeira mamada do potro, e armazenado a $-20^{\circ} \mathrm{C}$. As amostras foram avaliadas através de ELISA indireto. Os resultados obtidos demonstram que em comparação ao Grupo Controle, a vacina rEMA-2 foi capaz de estimular a produção de anticorpos vacinais nos Grupos Primovacinado e Revacinado. Éguas que receberam o reforço vacinal estimularam mais rapidamente a produção de anticorpos, tendo aumento percentual de $61 \%$ uma semana após a $1^{\text {a }}$ dose, enquanto éguas primovacinadas tiveram incremento de 8,35\% o título de anticorpos no mesmo período. Na resposta primária a uma vacina, após o contato com o antígeno, a expansão clonal de linfócitos leva em torno de 14 dias para produzir níveis detectáveis de anticorpos. Uma parte destes linfócitos irão se diferenciar em células de memória, que ao entrarem novamente em contato 
com o antígeno permitem que a produção de anticorpos seja mais rápida e intensa, conforme observado em nossos resultados. A média da absorbância e erro padrão da concentração de anticorpos no colostro foi: Grupo Primovacinado - $1.4013 \pm 0.2121$, Grupo Revacinado - $1.9027 \pm 0.0670$ e Grupo Controle $-0.9408 \pm$ 0.1311 , havendo diferença estatística entre os grupos. A vacinação de éguas gestantes geralmente contempla o terço final de gestação, justamente para que sejam concentrados anticorpos vacinais na glândula mamária no periparto, permitindo que o neonato os receba através de imunidade passiva. Observamos que a vacina rEMA-2 foi eficaz para a concentração de anticorpos no colostro, sendo ainda mais evidente no Grupo Revacinado. Éguas que receberam reforço da vacina rEMA-2 apresentaram memória imunológica, o que permitiu a produção mais rápida de anticorpos vacinais em comparação ao Grupo Primovacinado. Éguas que receberam reforço da vacina rEMA-2 obtiveram concentrações maiores de anticorpos no colostro, sugerindo que neonatos provenientes de éguas revacinadas recebam maior aporte de imunoglobulinas antiEMA-2 de T. equi através de imunidade passiva.

Palavras-chave: Theileria equi. Éguas gestantes. Vacina rEMA-2. 